\title{
COIL SPRING FOR TORQUE REDUCTION IN TRACTOR FOLDABLE ROPS
}

\author{
Guilherme de M. Araujo ${ }^{*}$, Marcos A. Teixeira ${ }^{2}$, Murilo A. Voltarelli ${ }^{3}$, \\ Wilson de A. Orlando Junior ${ }^{4}$, Leticia C. M. Tavares ${ }^{4}$
}

${ }^{1 *}$ Corresponding author. University of California, Davis/ Davis, Estados Unidos. E-mail: gdemoura@ucdavis.edu

\section{KEYWORDS}

tractor accidents, tractor rollover, torsion coil springs, agricultural tractors.

\begin{abstract}
Studies conducted by the international labor organization have shown that operations involving agricultural machinery are among the three activities with the highest risk of accidents to workers. Among the possible causes, rollover is the most common, accounting for $33 \%$ of fatal accidents. Despite this, there are standards that provide for the use of safety devices to ensure the physical integrity of the operator, among these equipment stand out rollover protection structures, which can be foldable or not. In this sense, the objective of this study was to perform an ergonomic study in order to analyze the torque required for lowering and lifting a foldable rollover protection structure attached to an agricultural tractor, developing instrumentation for validation of the efforts required to operate the structure and comparing the results obtained with the values recommended by the Standard (CODE 6 - OECD). When torque values were above those recommended by the standard, a set of torsion springs was used as solution to torque reduction. After further testing, the effectiveness of the solution was verified. Furthermore, it was observed that the angular speed of the bar does not have a significant influence on the torque required to lift the bar.
\end{abstract}

\section{INTRODUCTION}

The agricultural tractor is the most important source of power in the agricultural environment, contributing to the development and technological advancement of the Agricultural Production Systems (APS), as the only way to guarantee the gains of scale that are observed in the global Agribusiness. However, the tractor is also a source of risk of accidents and injuries to workers (Schlosser et al., 2002, Hoy, 2009, Macedo et al., 2015, Casazza et al., 2016, Lleras et al., 2016).

Springfeldt (1996) and Khorsandi et al. 2017 reported that within accidents involving agricultural tractors the primary cause is tractor rollover, Murphy \& Yoder (1998) mention that rollover accounts for a third of total fatalities involving agricultural workers.

In this sense, in order to minimize the risk of rollover in agricultural tractors, safety standards were put in place, including safety devices such as rollover protection structure (ROPS) (Myers, 2000; Ayers \& Rondelli, 2016; Li et al. 2016), which is also foreseen in the Brazilian standards, being more common the adoption of international standards, such as the Code 6 issued by the Organization for Economic Cooperation and Development (CODE 6 - OECD, 2012) (Ballesteros et al., 2015; Ayers et al., 2016).

However, rollover protection structures are not always a suitable alternative, because it increases the cost of the product (tractor), and make it difficult to work indoors and in places with limited height; such as animal confinement buildings, sheds and orchards. In order to approach this problem, the Foldable Rollover Protection Structures (FROPS) (Powers et al., 2001; Khorsandi et al., 2016) were proposed and implemented by the industry. Nevertheless, many of these bars present excessive weight (approximately $20.00 \mathrm{~kg}$ ) and are located at high height of the ground (approximately $1.90 \mathrm{~m}$ ), which lead the operator to refrain from returning the bar to its upper position, working with it in its lower position, which does not minimize rollover accidents. In cases where the FROPS torque (force) is too high a mechanical assist mechanism such as a torsion spring, can be designed and installed associated to the to the tractor FROPS.

\footnotetext{
${ }^{2}$ Universidade Federal Fluminense/ Niterói - RJ, Brasil

${ }^{3}$ Universidade Federal de São Carlos/ Buri - SP, Brasil.

${ }^{4}$ Universidade Federal de Viçosa/ Viçosa - MG, Brasil.

Received in: 8-23-2017

Accepted in: 8-9-2018
} 
In this sense, assuming that torsion springs can be used as part of a mechanical assist device (Rossi et al., 2015) for operators to handle the foldable rollover protection structure in a more ergonomic way, the objective of this study was to characterize the lifting and lowering (torque) of a Foldable Rollover Protection Structure, comparing the results obtained with the values recommended by the standard (CODE 6 - OECD). When verified that the quantified torque values were above the recommended by the standards a solution was proposed, implemented and tested to make sure it does correct the deviations found.

\section{MATERIAL AND METHODS}

Laboratory tests were conducted at the FARM MACHINERY LAB (FML), attached to the Biosystems Engineering Department in the College of Agricultural Sciences and Natural Resources (CASNR) at the University of Tennessee, Knoxville (USA). It was utilized for the experiment a Deere and Co. FROPS (Figure 1), this prototype is found in tractor models 4120, 4320, 4520 and 4720 .

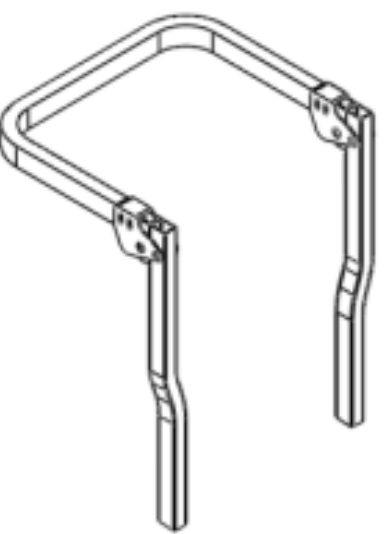

FIGURE 1. Schematic representation of the prototype used for laboratory tests (Khorsandi et al., 2016).

The FROPS adopted for the experiment has identification serial number 00544 and operated from $-40^{\circ}$ to $+90^{\circ}$. It is important to highlight that the chosen model was successfully approved in the SAE J2194 (2009) tests (Alfaro et al., 2010), (referring to longitudinal, transverse and vertical impact tests), since the OECD requires this approval in order to allow the Code 6 tests to be validated.

The determinations for the initial torque in the tested prototype and the resulting torque were performed by the torque measurement system proposed by Khorsandi et al. (2016), being composed of: reversible gear motor, torque transducer, accelerometer, data logger, platform, fork, speed controller, switch and battery (Figure 2).

The motor (model Groschop PM801-PL73) was mounted on a metal platform attached to the fixed section of the FROPS and its function was to provide torque for a fork that gripped the upper part of the FROPS (moving part).

When the fork received torque from the motor it caused the FROPS to rotate with angular speed. Meanwhile, the accelerometer measured the angle between the FROPS and a normal imaginary line, the torque transducer (model Omegadyne TQ420-2K) measured the torque applied by the fork to turn the FROPS up and down. All the data was stored in the data logger (Campbell Scientific CR23X model) for further analysis.

The speed controller (model IronHorse GSD1) was used to control the operation speed of the motor (RPM), the switch had the function of controlling the motor rotating direction (clockwise and counterclockwise). And finally, the battery (12 V - DC) had the function of supplying power to the motor. 


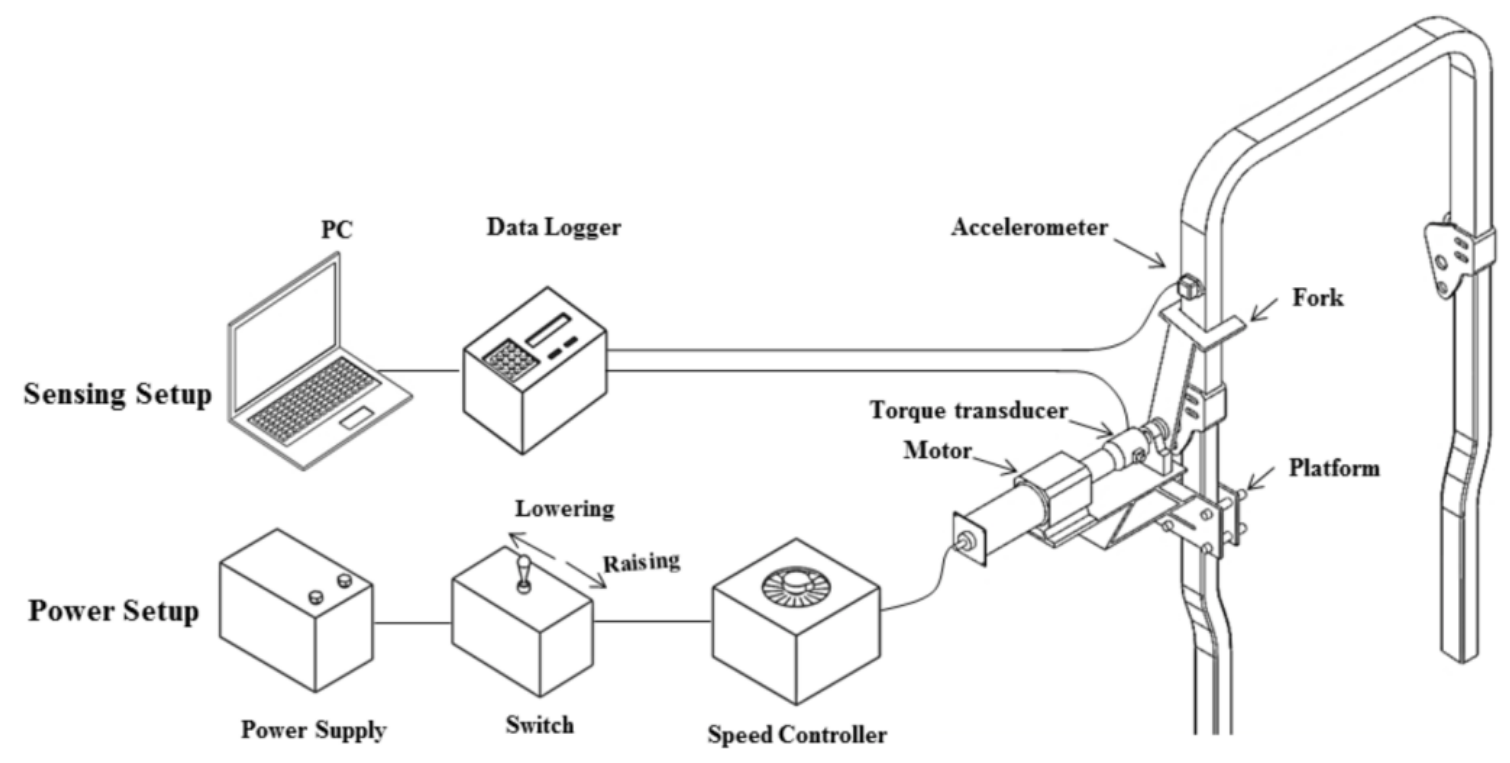

FIGURE 2. Schematization of the torque measurement system utilized to measure the actuating torque required to operate the FROPS (Khorsandi et al., 2016).

The force (torque) required to lift a FROPS is dependent of the ROPS folding section weight, the center of gravity (CG) and the friction between the moving and fixed parts of the structure (pivot location). Therefore, accurate measurements of the mass distribution and location of the center of gravity are needed (Ayers et al., 2016). Ayers et al. (2017) created a computer-based program named CRDP (Computer-Based ROPS Design Program) capable of determining the mass distribution in the FROPS section based on its dimensions (width, length, tube section and thickness) and material density. In the case of this experiment it was verified by the CRDP package that the distance between the center of gravity of the FROPS and the exact place where the pivot point is located is $0.60 \mathrm{~m}$.

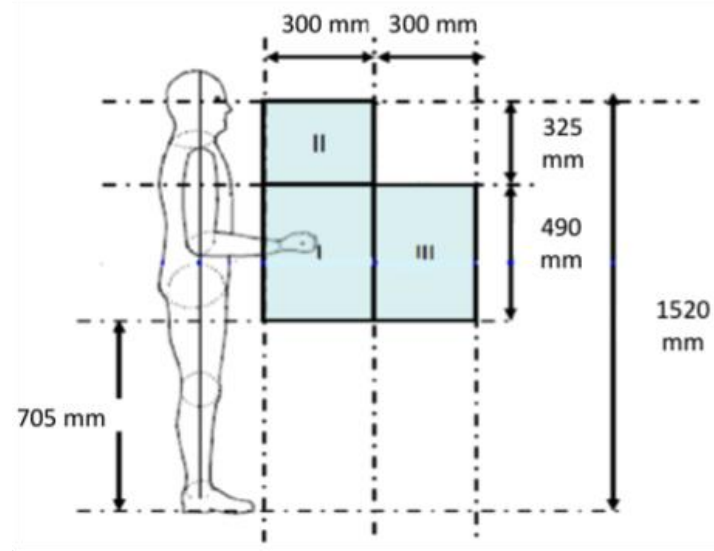

The maximum force applied by an operator, based on the standard, in order to handle the FROPS must vary between $50 \mathrm{~N}$ and $100 \mathrm{~N}$, as shown in Table 1, being a function of the operating zone in which the operator is located at (Figure 3) (CODE 6 - OECD).

TABLE 1. Maximum acceptable force to operate the FROPS as a function of the operating zone (CODE 6 OECD, 2012).

\begin{tabular}{cc}
\hline Zone & Acceptable Force (N) \\
\hline I & 100 \\
II & 75 \\
III & 50 \\
\hline
\end{tabular}

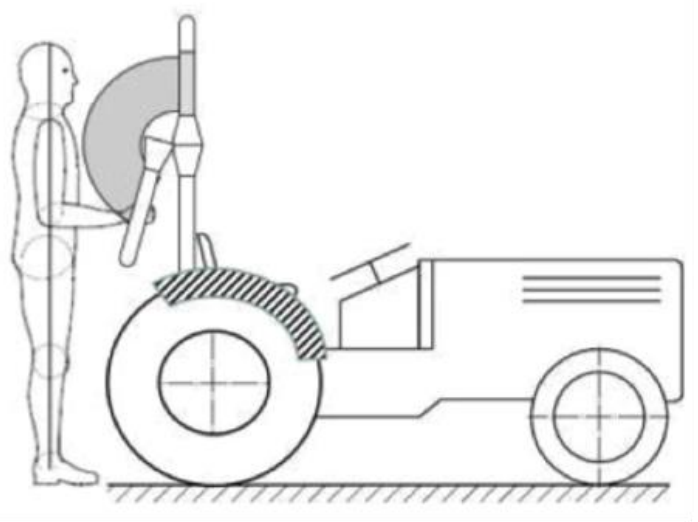

FIGURE 3. Schematic representation of FROPS operating zones based on a short-sized standing male operator (OECD, 2012).

According to OECD Code 6 these operating zones have been defined on the basis of a short-sized male operator or a mid-sized female operator who is standing and needs to raise or lower a roll bar. To help define the zones, a number of anthropometric data from standards and studies were considered, with the main approach being the ISO 6682 that defines zones of comfort and zones of reach for humans.
The spatial portion defined as Zone I is called a comfort zone, Zone II is called the accessible zone without forward leaning of the body, and Zone III is called the accessible zone with forward leaning of the body.

Therefore, the following equations were used in order to determine the maximum acceptable torque for each zone: 


$$
\begin{aligned}
& \text { Torque }_{\text {MAX Zone I }}=100 \mathrm{~N} \text { x } 0.60 \mathrm{~m}=60.0 \mathrm{~N} . \mathrm{m} \\
& \text { Torque }_{\text {MAX Zone II }}=75 \mathrm{~N} \text { x } 0.60 \mathrm{~m}=45.0 \mathrm{~N} . \mathrm{m} \\
& \text { Torque }_{\text {MAX Zone III }}=50 \mathrm{~N} \text { x } 0.60 \mathrm{~m}=30.0 \mathrm{~N} . \mathrm{m}
\end{aligned}
$$

The first term present in the equations refers to the applied force and varies as a function of the operation zone in which the operator is located at, according to Table 1. The second term refers to the lever arm of application force (distance between the CG of the FROPS and the pivot), this distance is fixed and equivalent to $0.60 \mathrm{~m}$.

In order to provide better conditions to the worker when operating a FROPS, it was proposed a solution that aimed at reducing the torque required to handle the FROPS and, consequently, the force applied by the operator. The solution adopted was the implementation of a set of 4 coil torsion springs, installed in pairs associated with the FROPS pivot point, as shown in Figure 4. Coil torsion springs were chosen as they are a helical-shaped springs capable of storing energy during the FROPS lowering process and releasing the stored energy during the FROPS raising process (Vuckelic \& Brcic, 2016), therefore assisting the operator. Not to mention that this spring type is available in various sizes, shapes and models in the commercial market, with a suitable acquisition cost (Sardou et al., 2005).

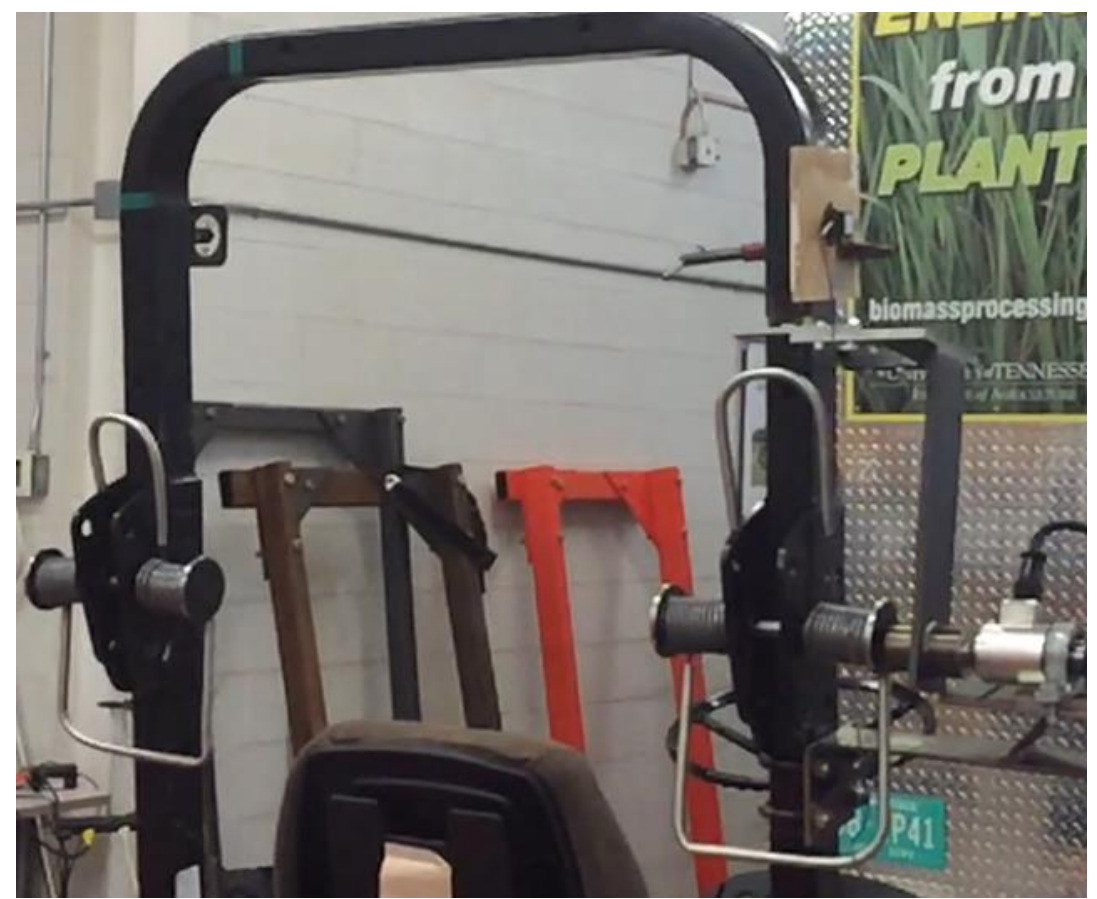

FIGURE 4. Set of coil torsion springs installed in pairs at each end of the fixed section of the FROPS.

In order to design the coil torsion springs an electronic spreadsheet model created from equations 4,5 , 6, 7, 8, and 9 was implemented. These equations are adaptations of HOOKE's law (1678) and were also used by several authors (Pöllänen \& Martikka, 2010; Choi \& Choi, 2015; Yıldırım, 2016) when studying the behavior of torsion springs in a wild variety of applications.

$$
\begin{aligned}
& \mathrm{S}=\frac{32 \times 10^{-6} \times \mathrm{Q}}{\pi \times \mathrm{d}^{3}} \\
& \mathrm{Q}=\mathrm{R} \cdot \mathrm{T} \\
& \mathrm{R}=\frac{10^{9} \times \mathrm{E} \cdot \mathrm{d}^{4}}{3888 \mathrm{n} \cdot \mathrm{D}} \\
& \mathrm{P}=\frac{\mathrm{Q}}{\mathrm{M}} \\
& \mathrm{DI}=\mathrm{D}-2 \mathrm{~d} \\
& \mathrm{~L}=\mathrm{d} \times \mathrm{n}
\end{aligned}
$$

Where,

\section{$\mathrm{S}$ : Bending Stress (MPa);}

Q: Torque (N.m); $\mathrm{d}$ : Wire diameter $(\mathrm{m})$;

R: Spring rate (N.m. ${ }^{\text {o-1 }}$;

$\mathrm{T}$ : Deflection $\left(^{\circ}\right)$;

E: Material Modulus of Elasticity (MPa);

$\mathrm{n}$ : Number of active coils;

D: Mean coil diameter $(\mathrm{m})$;

P: Force $(\mathrm{N})$;

M: Lever arm (m),

L: Spring length (m).

The model was solved with the help of Solver (Excel TM Add-in) software package, mentioned by a number of authors (Dasgupta, 2008; Arif et al., 2012; Ishizu \& Yamada, 2017) as a great auxiliary tool for optimizing nonlinear problems involving multiple variables. As input of the model the following constraints were considered: 
- Constraint 1: $0.0254 \mathrm{~m} \leq \mathrm{DI} \leq 0.0381 \mathrm{~m}$;

- Constraint 2: $60^{\circ} \leq \mathrm{T} \leq 135^{\circ}$;

- Constraint 3: $0.0015875 \mathrm{~m} \leq \mathrm{d} \leq 0.0079375 \mathrm{~m}$;

- Constraint 4: $0.06477 \mathrm{~m} \leq \mathrm{L} \leq 0.1190625 \mathrm{~m}$;

- Constraint 5: $\mathrm{M} \geq 0.3048 \mathrm{~m}$,

- Constraint 6: Q $\geq 11.30$ N.m.

These restrictions represent physical limitations (the spring length $\mathrm{L}$ can not exceed $0.12 \mathrm{~m}$, otherwise the spring will not fit in place intended for its installation) or desired final technical specifications such as the minimum $\mathrm{Q}$ torque supported by the spring.

Four repetitions were performed at two different speeds (4 RPM and 10 RPM) in order to measure the actuating torque required for the FROPS handling, two repetitions refer to the lowering process, and the other two refer to the lifting process. The results were elucidated in charts, comparing the actual torque data and the specific limits recommended by the OECD - CODE 6 standard. After the implementation of the proposed solution, the set was again submitted to torque measurement tests, with the aim of verifying the effectiveness of the proposed solution. It was performed an analysis of variance (ANOVA) by the $\mathrm{F}$ test at the 5\% level of significance, in order to verify the existence of significant statistical differences between the required torque to operate the FROPS as a function of the angular speed applied with and without the adopted solution (coil springs).

\section{RESULTS AND DISCUSSION}

As described in the methodology, four replications were initially performed in order to determine the actuating torque. Results are presented in Figure 5.

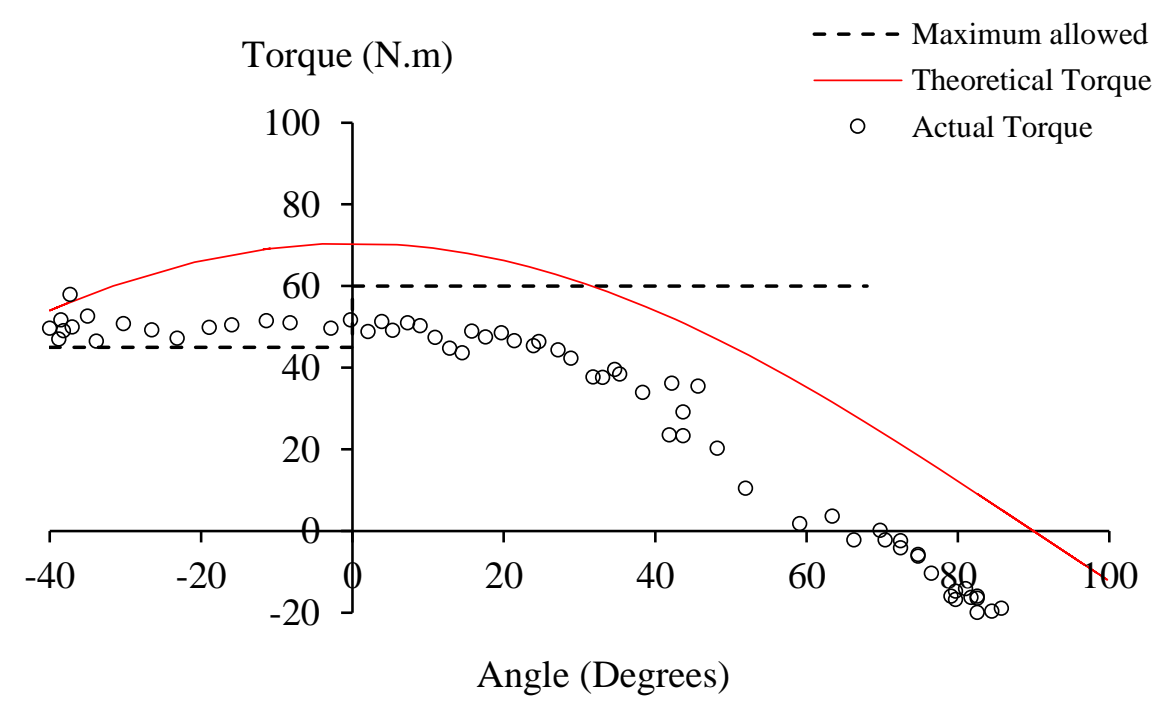

FIGURE 5a. Results from the lowering test of the FROPS at angular speed of 4 RPM.

It was observed that the results obtained experimentally referring to the torque required to lower the FROPS did not exceed the limits recommended by the OECD code 6 in the range of $100^{\circ}$ to $0^{\circ}$, referring to Zone I. However, after lowering the bar a little further, exceeding the $0^{\circ}$ mark, the operating zone changed (shifting from Zone I to Zone II), thereby the maximum acceptable torque recommended by the standard also changed (45 N.m), in such a way that the data contained below the $0^{\circ}$ mark overpassed the new imposed limits, becoming a problem. Besides, it was also noticed that there was a significant discrepancy between the torque values predicted by the theory (red curve) and the actual torque values, quantified in the laboratory tests. Ayers et al. (2016) proposed that this discrepancy is due to the friction between the FROPS and the joining pins between their fixed and the moving sections. 


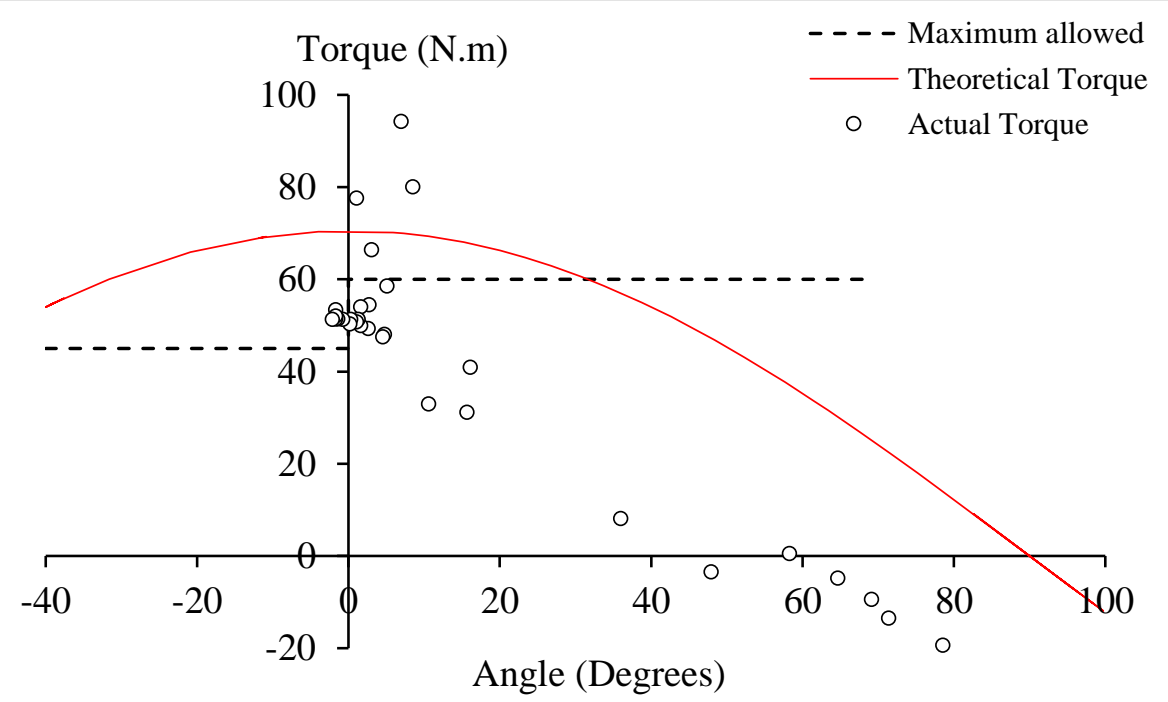

FIGURE 5b. Results from the lowering test of the FROPS at angular speed of 10 RPM.

It was verified that the results presented in figure $5 \mathrm{~b}$ presented similar behavior to the results presented in figure $5 \mathrm{a}$. Likewise, it was concluded that when the operator handles the FROPS in the range of $0^{\circ}$ to $-40^{\circ}$ his health might be compromised, due to the fact that he is applying a torque superior than the recommend by the standards. In addition, it is also observed that the angular speed of the FROPS did not have a direct influence on the torque required to lower the bar. Through the ANOVA, it was verified that the angular speed to lower the FROPS had no direct influence on the average torque required to lower the FROPS (p-value $=0.737$ ).

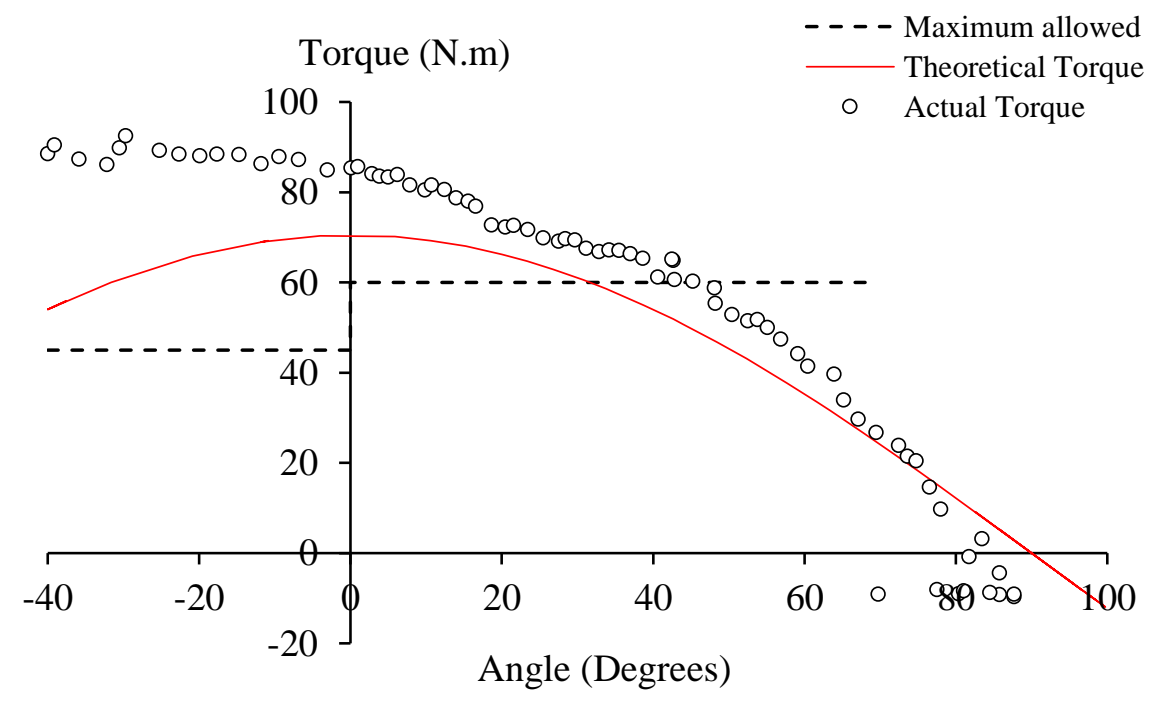

FIGURE 5c. Results from the lifting test of the FROPS at angular speed of 4 RPM.

Results presented in figure 5c suggest that in general the effort required to lift the FROPS is higher than the limits recommended by the OECD code 6 , especially in zone II, where acceptable values are more critical (actual data exceeds the maximum acceptable tolerances by almost $100 \%$ ). 


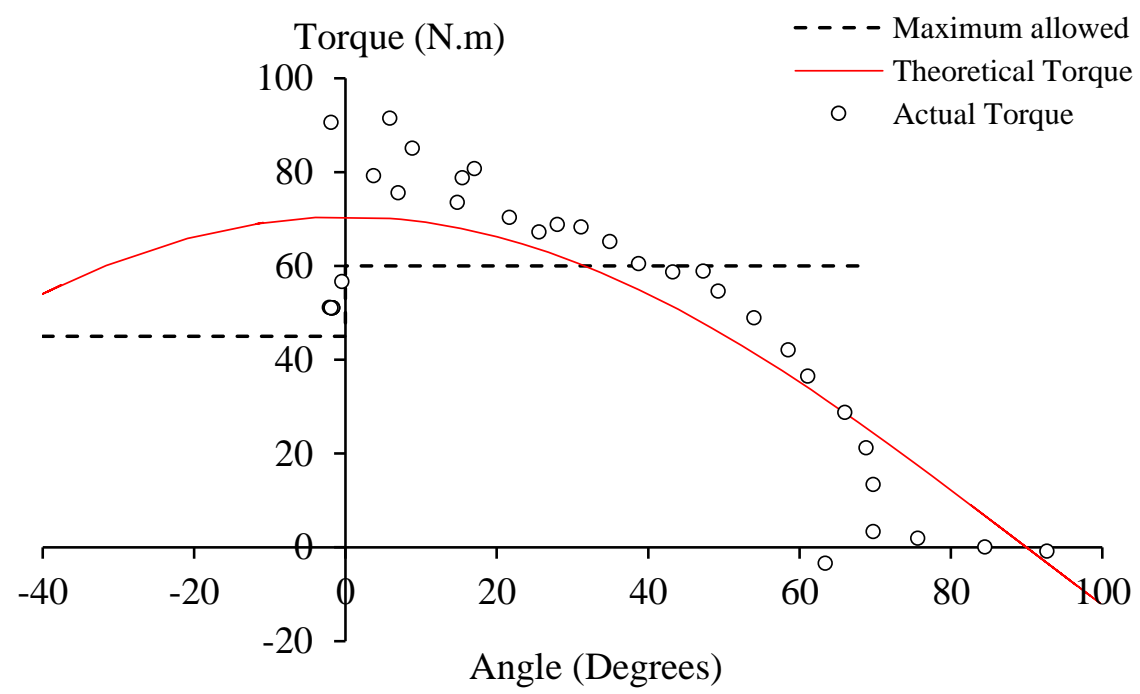

FIGURE 5d. Results from the lifting test of the FROPS at angular speed of 4 RPM.

As in the lowering tests of the FROPS, it was verified through the analysis of variance that the angular speed also did not present a direct influence on the torque to raise the EPCD (p-value $=0.777)$. Thus, it was concluded that the angular speed does not present significant influence on the torque required to operate the FROPS, either to lower it or lift it.

In a general context, it was experimentally proven that the torque required by an operator to raise the FROPS without any assist mechanism exceeded the limits imposed by the OECD code 6 , corroborating the results found by Khorsandi et al. (2016) and Ayers et al. (2016).

Table 2 below informs the output of the electronic model created to design the coil torsion spring elements.

TABLE 2. Design elements of the coil torsion spring obtained by the electronic spreadsheet model.

\begin{tabular}{lcc}
\hline \multicolumn{1}{c}{ Element } & Value & Unity \\
\hline Mean Coil Diameter (D) & 3.81 & $\mathrm{~cm}$ \\
Deflection (T) & 105 & $\circ$ \\
Lever arm (M) & 30.48 & $\mathrm{~cm}$ \\
Number of active coils (n) & 16.40 & - \\
Spring rate (R) & 0.13 & N.m. ${ }^{\circ-1}$ \\
Modulus of Elasticity (E) & 207 & $\mathrm{GPa}$ \\
Wire diameter (d) & 6.20 & $\mathrm{~mm}$ \\
\hline
\end{tabular}

The model output matched the constraints imposed on the input of the model (for example, the adopted deflection of $105^{\circ}$ was between the limits of $60^{\circ}$ and 135 ${ }^{\circ}$ ) (Table 2). An interesting parameter to be analyzed is the stiffness coefficient of the spring; it was observed that this spring had a capacity to store 0.13 N.m at each degree that it is turned during the lowering of the FROPS (Table 2).

Once the designing spring elements were known it was possible to calculate the greatnesses referring to the spring. Table 3 shows the greatnesses of the idealized spring.
TABLE 3. Resultant greatnesses characteristic of the torsion spring designed from the model implemented in electronic spreadsheet.

\begin{tabular}{lcc}
\hline \multicolumn{1}{c}{ Greatness } & Magnitude & Unity \\
\hline Bending Stress (S) & 564.40 & $\mathrm{MPa}$ \\
Torque (Q) & 13.65 & N.m \\
Force (P) & 44.78 & $\mathrm{~N}$ \\
\hline
\end{tabular}

From the data presented in table 3, it is valuable to highlight the torque, which indicates the maximum amount of energy that could be stored by the spring without compromising its structure. Additionally, it was verified that by multiplying the maximum spring deflection $\left(105^{\circ}\right)$ by the spring rate $\left(0.13 \mathrm{Nm}^{\mathrm{o}-1}\right)$ the result obtained was 13.65 N.m, which was exactly the value informed for the maximum torque supported by the spring. The same was true for all the other equations (4 to 9) previously presented, indicating the reliability of the electronic spreadsheet model.

As there were a limited number of commercial models available, it was chosen to purchase a set that most closely resembled the calculated elements, making sure that the choice did not exceed any of the constraints previously imposed by the model. Table 4 presents the characteristics of the spring that was purchased and later implemented.

TABLE 4. Technical specifications of the torsion spring acquired and later implemented.

\begin{tabular}{lcc}
\hline \multicolumn{1}{c}{ Element } & Value & Unity \\
\hline Mean Coil Diameter (D) & 5.56 & $\mathrm{~cm}$ \\
Deflection (T) & 65 & $\circ$ \\
Moment arm (M) & 30.48 & $\mathrm{~cm}$ \\
Number of active coils (n) & 12.50 & - \\
Spring rate (R) & 0.30 & N.m. ${ }^{\circ-1}$ \\
Modulus of Elasticity (E) & 207 & $\mathrm{MPa}$ \\
Wire diameter (d) & 7.94 & $\mathrm{~mm}$ \\
\hline
\end{tabular}


It was verified that the characteristics of the acquired spring also respected the previously established restrictions. Furthermore, it was observed that the purchased spring was stronger than the first spring idealized; as it presented less number of coils, smaller mean diameter and greater wire diameter, as also observed in Yıldırım (2016) studies with helical springs. Finally, it was noticed that there was an increase in the spring rate $\left(0.30 \mathrm{~N} . \mathrm{m}^{-1}\right)$, since the maximum deflection of the purchased spring was smaller than the maximum deflection of the first calculated spring, the second one must have had a higher unitary capacity of power storage.

In order to obtain a better understanding of the mechanical behavior of the acquired springs, the values present in Table 4 were applied to the equations 4 to 9 to calculate the suitability of the purchased springs to the application. Results are shown in table 5.
TABLE 5. Resultant greatnesses characteristic of the torsion spring.

\begin{tabular}{lcc}
\hline \multicolumn{1}{c}{ Greatness } & Magnitude & Unity \\
\hline Bending Stress (S) & 402.7 & $\mathrm{MPa}$ \\
Torque (Q) & 19.79 & N.m \\
Force (P) & 6.49 & $\mathrm{~N}$ \\
\hline
\end{tabular}

The new spring had greater torque resistance if compared to the first spring, which also supported the conclusion that it was a stronger spring, compared to the theoretical proposed one.

As the spring was adapted to the FROPS, new tests were performed and the results can be seen in Figures $6 \mathrm{a}$ and $6 \mathrm{~b}$, which illustrate the comparison of the torque required to lift the FROPS without an assist mechanism and after the implementation of the spring set:

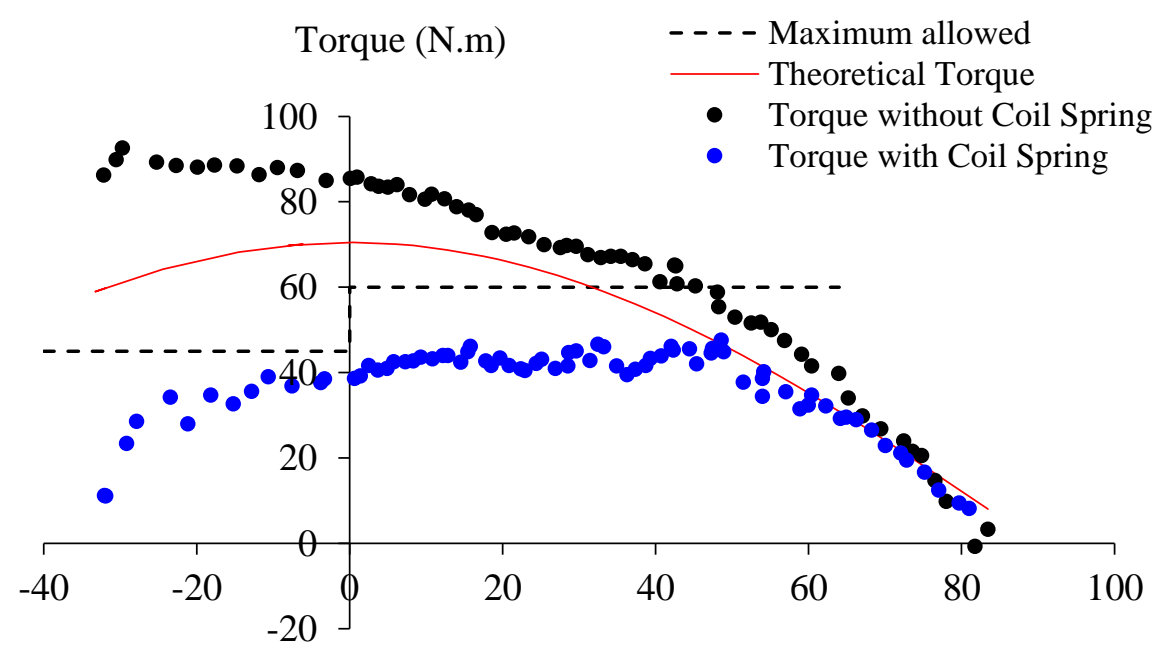

Angle (Degrees)

FIGURE 6a. Comparison between the torque required to lift the FROPS without an assist mechanism and the resulting torque after the implementation of the spring set at the speed of 4 RPM.

Through the ANOVA it was verified that the implementation of the spring assembly significantly reduced the torque required to lift the FROPS ( $\mathrm{p}$-value $=1.474 \times 10^{-10}$ ) at the angular speed of 4RPM. In addition, it was observed that the new torque values were below the maximum values recommended by code 6 of the OECD.

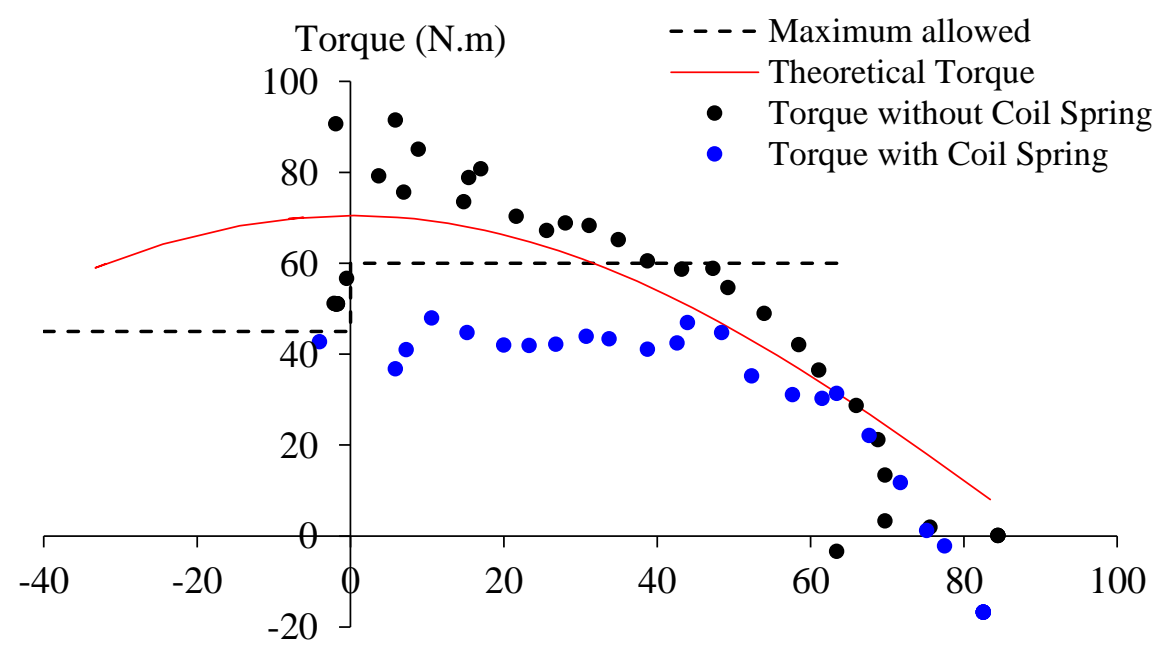

Angle (Degrees)

FIGURE 6b. Comparison between the torque required to lift the FROPS without an assist mechanism and the resulting torque after the implementation of the spring set at the speed of 10 RPM. 
It was observed through the ANOVA that the implementation of the spring set significantly reduced the torque required to lift the FROPS ( $\mathrm{p}$-value $=0.024$ ), this time at the angular speed of 10 RPM. In addition, it was also observed through the ANOVA that the angular speed does not present a direct influence on the torque to raise the FROPS with mechanical assistance to the operator ( $p$ value $=0.609)$. Thus, it was concluded that the angular speed does not present significant influence on the torque required to operate the FROPS, either in its lowering or lifting, with or without mechanical assistance to the operator.

Finally, it was verified that the greater the angle in which the bar is positioned, the lower is the difference between the torque required to raise the bar with and without the set of springs (spring effectiveness). It could be seen that from the angle equivalent to $60^{\circ}$ upwards the set of springs had practically no effect at all.

This occurrence can be associated with the spring's initial deflection, in such a way that it only begins to be actually compressed from a certain angle, i.e., the smaller the vertical displacement of the FROPS the smaller the amount of energy stored by the spring and consequently the lower its effectiveness. To support this theory, it was verified that the biggest differences between the torque with and without the torsion springs were found in the smaller angle values, which indicates the higher compression of the spring and consequently, the greater energy stored to assist the operator to raise the bar.

\section{CONCLUSIONS}

It was verified that the torsion spring set has proven to be effective in reducing the torque required to operate the foldable rollover protection structure at angles below $60^{\circ}$, reducing by almost $40 \%$ the values recommended by OECD code 6 .

The angular speed at which the foldable rollover protection structure is operated has little or no influence on the required torque.

\section{ACKNOWLEDGMENTS}

The authors would like to thank the Coordenação de Aperfeiçoamento de Pessoal de Nível Superior (CAPES) for the financial support, and the University of Tennessee research team, for the given opportunity to realize this research.

\section{REFERENCES}

Alfaro JR, Arana I, Arazuri S, Jarén C (2010) Assessing the safety provided by SAE J2194 Standard and Code 4 Standard code for testing ROPS, using finite element analysis. Biosystems Engineering 105(2):189-197. DOI: http://doi.org/10.1016/j.biosystemseng.2009.10.007

Arif C, Setiawan BI, Sofiyuddin HA, Martief LM, Mizoguchi M, Doi R (2012) Estimating Crop Coefficient in Intermittent Irrigation Paddy Fields Using Excel Solver. Rice Science 19(2):143-152. DOI: https://doi.org/10.1016/S1672-6308(12)60033-X
Ayers P, Khorsandi F, John Y, Whitaker G (2017) Rops Design Development and Evaluation of a Computer-Based ROPS Design Program. Journal of Agricultural Safety and Health 22(4):247-260. DOI: http://dx.doi.org/10.13031/jash.22.11745

Ayers P, Khorsandi F, Wang X, Araujo, GM (2016) Rops Design to Protect Operators During Tractor Rollovers. In: International Society for Terrain Vehicle System. Detroit, 8th Americas Conference, Proceedings...

Ayers P, Rondelli V (2016). Tractor ROPS and Stability Research: Introduction to this Special Issue. Journal of Agricultural Safety and Health 22(4):213-214. DOI: http://dx.doi.org/10.13031/jash.22.12127

Ballesteros T, Arana JI, Ezcurdia AP, Alfaro JR (2015) Development and validation of automatically deployable ROPS based on airbag inflator technology. Biosystems Engineering 130:92-105. DOI:

http://dx.doi.org/10.1016/j.biosystemseng.2014.12.007

Casazza C, Martelli R, Rondelli V (2016) Evaluation of a Commercial Tractor Safety Monitoring System Using a Reverse Engineering Procedure. Journal of Agricultural Safety and Health 22(4):215-225. DOI: http://dx.doi.org/10.13031/Jash.22.11667

Choi BL, Choi BH (2015) Numerical method for optimizing design variables of carbon-fiber-reinforced epoxy composite coil springs. Composites Part B: Engineering 82(1):42-49. DOI:

http://doi.org/10.1016/j.compositesb.2015.08.005

Dasgupta PK (2008) Chromatographic peak resolution using Microsoft Excel Solver: The merit of time shifting input arrays. Journal of Chromatography A 1213(1):50-55. DOI: http://doi.org/10.1016/j.chroma.2008.08.108

Hoy RM (2009) Farm tractor rollover protection: Why simply getting rollover protective structures installed on all tractors is not sufficient. Journal of Agricultural Safety and Health 15(1):3-4.

Ishizu H, Yamada T (2017) Absolute peak-efficiency calibration of a well-type germanium detector using multiple gamma-emitting nuclides with the "Solver" addin in Excel ${ }^{\mathrm{TM}}$. Applied Radiation and Isotopes 126:158161. DOI: http://doi.org/10.1016/j.apradiso.2017.02.013

Khorsandi F, Ayers P, Jackson D, Wilkerson J (2016) The Effect of Speed on Foldable Rops Actuation Forces. Journal of Agricultural Safety and Health 22(4):285-298. DOI: http://dx.doi.org/10.13031/Jash.22.11752

Khorsandi F, Ayers P, Truster, TJ (2017) Developing and Evaluating a Finite Element for Predicting the Two-Post Rollover Protection Structure Nonlinear Behavior Using SAE J2194 Static Test. Biosystems Engineering 156:96107. DOI:

http://dx.doi.org/10.1016/J.Biosystemseng.2017.01.010 
Li Z, Mitsuoka M, Inoue E, Okayasu T, Hirai Y, Zhu Z (2016) Parameter sensitivity for tractor lateral stability against Phase I overturn on random road surfaces. Biosystems Engineering 150:10-23. DOI: http://dx.doi.org/10.1016/j.biosystemseng.2016.07.004

Lleras NO, Brennan S, Murphy D, Klena MJ, Garvey PM, Somer III HJ (2016) Development of an Open-Source Tractor Driving Simulator for Tractor Stability Tests. Journal of Agricultural Safety and Health 22(4):227-46. DOI: http://dx.doi.org/10.13031/jash.22.11774

Macedo DXS, Monteiro LA, Santos VC, Albierto D, Chioderoli CA (2015) Caracterização dos acidentes com máquinas agrícolas em rodovias federais no estado do Rio Grande do Sul. Ciência Rural 45(1):43-46. DOI: http://dx.doi.org/10.1590/0103-8478cr20140333.

Macedo DXS, Monteiro LA, Santos VC, Costa E, Dutra JAC (2016) Acidentes com Tratores Agrícolas nas Rodovias Federais no Estado de Goiás. Energia na Agricultura 31(3):223-230. DOI:

http://dx.doi.org/10.17224/EnergAgric.2016v31n3p223230

Murphy DJ, Yoder A (1998) Census of fatal occupational injury in the agriculture, forestry, and fishing industry. Journal of Agricultural Safety and Health 4(5):55. DOI: http://dx.doi.org/10.1017/S025292110004450X

Myers ML (2000) Prevention Effectiveness of Rollover Protective Structures-Part I: Strategy Evolution. Journal of Agricultural Safety and Health 6(1):29-40. DOI: http://dx.doi.org/10.13031/2013.17812.

OECD - Organization for Economic Co-Operation and Development (2012) OECD Standard Code for the Official Testing of Front Mounted Roll-Over Protective Structures on Narrow-Track Wheeled Agricultural and Forestry Tractors: CODE 6. Paris.

Pöllänen I, Martikka H (2010) Optimal re-design of helical springs using fuzzy design and FEM. Advances in Engineering Software 41(3):410-414. DOI: http://doi.org/10.1016/j.advengsoft.2009.03.010
Powers JR, Harris JR, Etherton JR, Ronaghi M, Snyders KA, Lutz TJ, Newbraugh BH (2001) Preventing Tractor Rollover Fatalities: Performance of the NIOSH autoROPS". Injury Prevention. Journal of the International Society for Child and Adolescent Injury Prevention 7(Suppl 1):i54-58. DOI: http://dx.doi.org/10.1136/ip.7.suppl_1.i54

Rossi F, Castellani F, Nicolini A (2015) Benefits and Challenges of Mechanical Spring Systems for Energy Storage Applications. Energy Procedia 82: 805-810. DOI: https://doi.org/10.1016/j.egypro.2015.11.816

Sardou M, Damotte E, Zunino C, Djomseu P (2005) Light Weight, Low Cost, Composite Coil Springs are a Reality. SAE Technical Paper 2005-01-1698. DOI: http://dx.doi.org.br/10.4271/2005-01-1698.

SAE - Society of Automotive Engineers (2009) Roll-Over protective structures (ROPS) for wheeled agricultural tractors.

Schlosser JF, Debiasi H, Parcianello G, Rambo L (2002) Characterization of the accidents involving agricultural tractors. Ciência Rural 32:977-981. DOI: http://dx.doi.org/10.1590/S0103-84782002000600010

Springfeldt B (1996) Rollover of tractors — international experiences. Safety Science 24(2):95-110. DOI: http://dx.doi.org/10.1016/S0925-7535(96)00069-0

Vuckelic G, Brcic M (2016) Failure Analysis of a motor vehicle coil spring. Procedia Structural Integrity 2:29442950. DOI: https://doi.org/10.1016/j.prostr.2016.06.368

Y1ldirım V (2016) Exact determination of the global tip deflection of both close-coiled and open-coiled cylindrical helical compression springs having arbitrary doublysymmetric cross-sections. International Journal of Mechanical Sciences 115-116:280-298. 